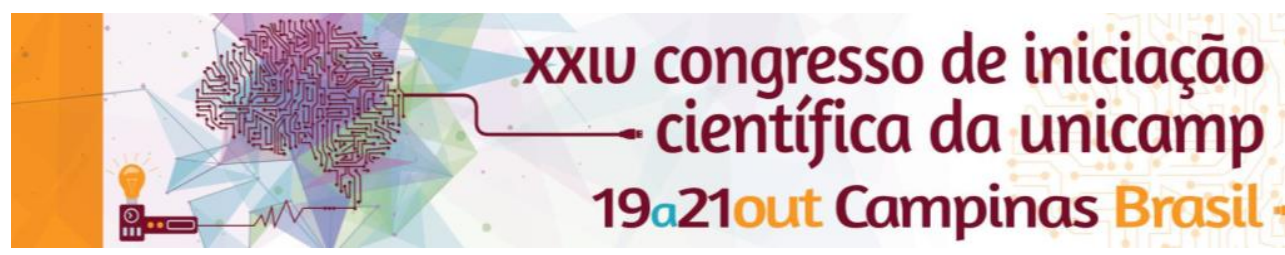

\title{
Introdução à pesquisa operacional: modelagem matemática e resolução de problemas
}

\author{
Fernanda C. D. Prim*, Felipe Ferrari* ${ }^{\star}$ Cristiano Torezzan
}

\section{Resumo}

Neste projeto, estudamos aplicações de programação linear, com ênfase na modelagem dos problemas e na utilização de solvers, em particular do MSExcel. Diversos problemas clássicos foram estudados e, como um aprofundamento, apresentamos um caso do problema do caixeiro viajante que consiste em encontrar uma rota com a menor distância possível para uma viagem de avião, em linha reta, percorrendo todas as capitais brasileiras.

\section{Palavras-chave}

Programação Linear, Excel, Caixeiro Viajante.

\section{Introdução}

A Pesquisa Operacional (PO) é uma área interdisciplinar cujo interesse contemporâneo é estudo de métodos analíticos para tomada de decisão, num sentido amplo. Dentre os vários tópicos de interesses em $\mathrm{PO}$, a programação linear exerce um papel central em função de sua vasta aplicabilidade em situações reais e da existência de métodos eficientes para solução de problemas de grande porte.

Ao longo deste estudo, diversos problemas foram modelados e resolvidos através do solver do Excel. Dentre eles destacamos os problemas do mix de produção, dieta, alocação de produtos em prateleiras de supermercado, n-rainhas, mochila, alocação de vagões.

Como tema mais aprofundado de aplicação, escolheu-se o problema do caixeiro viajante, tendo como motivação principal a criação de uma rota mínima para uma viagem aérea envolvendo todas capitais brasileiras e o Distrito Federal

O problema foi resolvido através de duas abordagens: (i) solução exata do modelo utilizando o método simplex implementado no OpenSolver em Excel e (ii) uma Heurística evolutiva que acompanha o o Solver do Excel. Ambas resoluções chegaram ao mesmo resultado e a solução encontrada é apresentada na próxima seção.

\section{Resultados e Discussão}

O problema do caixeiro viajante pode ser definido, de acordo com Colin, 2015, da seguinte forma:

Seja um conjunto de nós $V=\{1,2, \ldots, n\}$ e um outro de $\operatorname{arcos} A$. Os nós representam as cidades. Os arcos representam pares ordenados de cidades entre as quais uma viagem é possível. Para o arco $(i, j) \in A, d_{i j}$ é a distância da viagem da cidade $i$ para a cidade $j$. O problema consiste em achar uma rota que inicia e termina na cidade 1 (ou qualquer outra cidade do conjunto de cidades), que visita todas as cidades apenas uma vez e que tenha a distância de viagem mínima.

Suponha que $x_{i j}=1$ represente que a cidade $j$ foi visitada imediatamente após a cidade $\mathrm{i}$; se isso não acontecer $x_{i j}=0$.

Uma formulação possível para o problema é:

$$
\min z=\sum_{i=1}^{n} \sum_{j=1}^{n} d_{i j} x_{i j}
$$

Sujeito à:

$\sum_{i=1}^{n} x_{i j}=1 \quad(j=1,2, \ldots, n)$ (saída)

$\sum_{j=1}^{n} x_{i j}=1 \quad(i=1,2, \ldots, n)$ (chegada)

$u_{i}-u_{j}+n x_{i j} \leq n-1 \quad(i \neq j ; i=2,3, \ldots, n ; j=2,3, \ldots$,

n)

$x_{i j} \in\{0,1\}, u_{j} \geq 0(j=1,2, \ldots, n ; i=1,2, \ldots, n)$

Como forma alternativa de solução, utilizamos também uma heurística evolutiva que está presente no solver do Excel. Ambas soluções chegaram a mesma resposta e um comparativo de tempo é apresentado na Tabela 1. A Figura 1 apresenta um mapa com a rota ótima obtida.

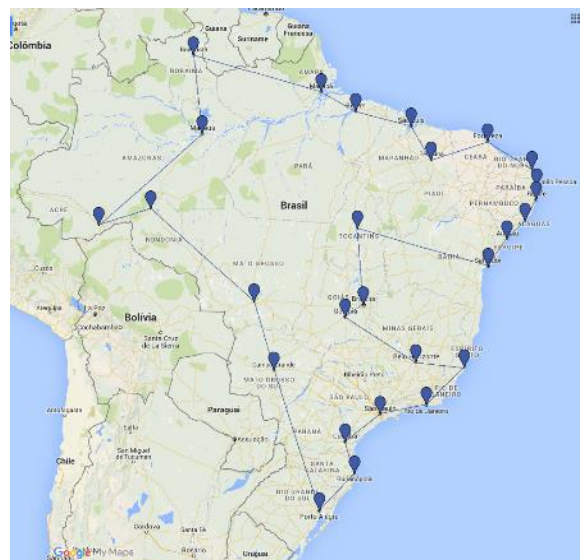

Figura 1. Rota mínima para uma viagem de carro entre as capitais brasileiras.

Tabela 1. Comparação entre os dois métodos de solução

\begin{tabular}{|l|c|c|}
\hline \multicolumn{1}{|c|}{ Método } & Tempo solução $(\mathbf{s})$ & Distância $(\mathbf{K m})$ \\
\hline Exato & 7 & 15.464 \\
\hline Heurística & $>60$ & 15.464 \\
\hline
\end{tabular}

\section{Conclusões}

Neste trabalho estudamos problemas que podem ser modelados como problemas de programação linear e utilizamos solvers de planilhas eletrônicas para resolvêlos. Em especial, apresentamos uma aplicação do problema do caixeiro viajante para construir uma rota entre as capitais brasileiras.

\section{Agradecimentos}

Agradecemos ao programa PIBIC-EM e ao CNPq pelo apoio financeiro ao projeto.

Colin, E.; Pesquisa Operacional: 170 aplicações em Estratégia, Finanças, Logística, Produção, Marketing e Vendas. Rio de Janeiro, LTC, 2015. 